Jurnal Keperawatan Silampari

Volume 2, Nomor 1, Desember 2018

e-ISSN: 2581-1975

p-ISSN: 2597-7482

DOI: https://doi.org/10.31539/jks.v2i1.382

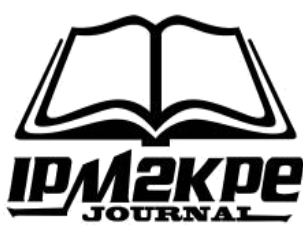

\title{
EFEKTIVITAS ISOMETRIC HANDGRIP EXERCISE DAN SLOW DEEP BREATHING EXERCISE TERHADAP PERUBAHAN TEKANAN DARAH PADA PENDERITA HIPERTENSI
}

\author{
Juli Andri ${ }^{1}$, Agung Waluyo ${ }^{2}$, Wati Jumaiyah ${ }^{3}$, Dhea Nastashia ${ }^{4}$ \\ Program Studi Ilmu Keperawatan, Universitas Muhamadiyah Bengkulu ${ }^{1}$ \\ Program Studi Ners, Universitas Indonesia ${ }^{2}$ \\ Program Studi Magister Keperawatan, Universitas Muhammadiyah Jakarta ${ }^{3,4}$ \\ Juli_Andri0788@yahoo.co.id ${ }^{1}$
}

\begin{abstract}
ABSTRAK
Penelitian ini bertujuan untuk mengidentifikasi efektifitas isometric handgrip exercise dan slow deep breathing exercise terhadap perubahan tekanan darah pada penderita hipertensi. Desain penelitian quasi experimental dengan rancangan penelitian two group pretest postest pada 32 responden. Hasil penelitian menunjukkan bahwa ada perubahan tekanan darah sistolik dan diastolik setelah dilakukan intervensi isometric handgrip exercise $(\mathrm{t}=8,279, \mathrm{p}=0,000),(\mathrm{t}=6,154, \mathrm{p}=0,000)$, serta terjadi perubahan tekanan darah sistolik dan diastolik setelah diberikan intervensi slow deep breathing exercise $(\mathrm{t}=3,632$, $\mathrm{p}=0,002),(\mathrm{t}=4,226, \mathrm{p}=0,001)$. Simpulan, baik isometric handgrip exercise maupun slow deep breathing exercise dapat menurunkan tekanan darah sistolik dan diastolik secara bermakna pada pasien hipertensi.
\end{abstract}

Kata Kunci: Hipertensi, Isometric Handgrip Exercise, Slow Deep Breathing Exercise, Tekanan Darah

\section{ABSTRACT}

This study aims to identify the effectiveness of isometric handgrip exercise and slow deep breathing exercise on changes in blood pressure in patients with hypertension. Quasi experimental research design with a two group pretest posttest research design on 32 respondents. The results showed that there was a change in systolic and diastolic blood pressure after an Isometric Handgrip Exercise intervention $(t=8,279, p=$ $0,000),(t=6,154, p=0,000)$, and changes in systolic and diastolic blood pressure after a slow deep intervention was given breathing exercise $(t=3,632, p=0,002),(t=$ 4,226, $p=0,001)$. Conclusion, both isometric handgrip exercise and slow deep breathing exercise can significantly reduce systolic and diastolic blood pressure in hypertensive patients.

Keywords: Hypertension, Isometric Handgrip Exercise, Slow Deep Breathing Exercise, Blood Pressure 


\section{PENDAHULUAN}

Penyakit hipertensi adalah salah satu penyakit tidak menular dimana memiliki prevalensi yang tinggi dan cenderung mengalami peningkatan (Suiraoka, 2012; Sutanto, 2010). Secara global prevalensi hipertensi diperkirakan mencapai $30 \%$ dari total populasi dan merupakan penyebab kematian sebesar 7,1 juta per tahun (Mortimer, 2011). Prevalensi ini diprediksi akan terus meningkat sebanyak 29\% pada tahun 2025. Terdapat satu miliar orang di dunia menderita hipertensi dengan tekanan darah sistolik $\geq 140 \mathrm{mmHg}$ dan tekanan darah diastolik $\geq 90 \mathrm{mmHg}$, dari $2 / 3$ diantaranya berada di negara berkembang yang berpenghasilan rendah sampai sedang(WHO, 2015). Urbanisasi yang cepat, gaya hidup, junkfood, dan stress merupakan faktor risiko yang bertanggung jawab untuk terjadinya peningkatan prevalensi hipertensi (Garg, Malhotra, Dhar, \& Tripathi, 2013).

Berdasarkan Region WHO, Indonesia menempati urutan ke 2 penderita hipertensi tertinggi di South East Asia setelah Myanmar (WHO, 2013). Prevalensi hipertensi di Indonesia ini merupakan salah satu masalah kesehatan dangan angka kejadian yang tinggi yaitu sebesar 25,8\%. Terdapat 5 wilayah di Indonesia dengan angka kejadian hipertensi tertinggi, yaitu di Bangka Belitung $(30,9)$, diikuti daerah Kalimantan Selatan $(30,8 \%)$, Kalimantan Timur $(29,6)$, Jawa Barat $(29,4 \%)$, dan Gorontalo $(29,4 \%)$. Sedangkan prevalensi hipertensi di Provinsi Bengkulu sudah mencapai sebesar 21,6\% (Riskesdas, 2013). Data dari Profil Kesehatan Provinsi Bengkulu sudah mencapai 54,66\% dengan kasus hipertensi (Dinkes Provinsi bengkulu, 2016). Dengan tingginya angka kejadian hipertensi yang ada di Indonesia namun upaya untuk mengendalikan hipertensi tersebut masih kurang, perlu adanya berbagai macam upaya yang bisa dilakukan untuk mengendalikan angka kejadian hipertensi yang tinggi tersebut sehingga dapat menekan angka hipertensi.

Global action plan direkomendasikan oleh WHO tahun 2014 dalam upaya mengendalikan prevalensi penyakit tidak menular meliputi pengendalian faktor risiko seperti merokok, konsumsi diet tinggi garam, ketidakaktifan fisik dan pengendalian stress atau psikologis. Oleh karena itu peningkatan aktivitas fisik dan manajemen stress sangat direkomendasikan sebagai salah satu strategi preventif dan promotif. Aktivitas fisik merupakan salah satu alternatif yang dikembangkan dalam upaya untuk menurunkan tekanan darah (Carlson, Dieberg, Hess, Millar, \& Smart, 2014). Penelitian sebelumnya juga mengidentifikasi bahwa upaya agar tekanan darah pada penderita hipertensi menurun bisa dilakukan dengan cara aktivitas fisikyang dapat memberi manfaat besar pada segala usia dan juga memiliki hubungan positif terhadap penurunan kasus penyakit kardiovaskular pada penderita hipertensi sebesar 50\% (James et al., 2014; Parlindungan \& Lukitasari, 2016). Sehingga dikembangkan latihan isometric sebagai salah satu terapi potensial untuk hipertensi (Mortimer, 2011). Latihan isometric meskipun sebelumnya dikaitkan dengan respon peningkatan tekanan darah, beberapa penelitian terbaru menyarankan latihan ini untuk menjadi salah satu pengobatan nonfarmakologis untuk tekanan darah (Carlson et al., 2014). Latihan relaksasi juga ditemukan efektif dilakukan pada pasien dengan hipertensi agar tekanan darah bisa terkontrol dan dapat mengendalikan stress.

Latihan isometric merupakan bentuk latihan statis yang terjadi bila otot berkontraksi tanpa adanya perubahan pada panjang otot atau pergerakan sendi yang terlihat. Latihan ini dapat dilakukan di mana saja, intensitas dari ringan ke sedang, penggunaan alat relatif lebih murah dan waktu yang diperlukan relatif lebih sedikit membuat latihan ini memiliki potensial untuk kepatuhan pada klien (Carlson et al, 
2014). Latihan isometrik yang dikembangkan sebagai salah satu terapi latihan untuk menurunkan tekanan darah adalah dengan menggunakan handgrip. Handgrip merupakan alat yang biasa digunakan untuk mengukur kekuatan otot genggaman tangan yang sangat penting untuk setiah aktivitas sehari-hari dan olahraga. Dari pernyataan ilmiah tentang pendekatan alternatif untuk menurunkan tekanan darah, American Heart Association (AHA) didukung panduan perangkat pernapasan dan pelatihan isometric handgrip menjelaskan bahwa isometric handgrip sebagai terapi pembantu yang efektif untuk penurunan tekanan darah dan setuju untuk digunakan secara klinis (McGowan et al, 2017). Latihan isometric handgrip dapat menurunkan reaktivitas kardiovaskuler terhadap stressor psikofisiologis pada orang dengan tekanan darah tinggi (Badrov, Horton, Millar, \& Mcgowan, 2013). Penelitian sebelumnya yang dilakukan pada responden yang mengalami hipertensi juga menjelaskan bahwa pasien yang diberikan latihan isometric handgrip selama 5 hari berturut-turut memperlihatkan penurunan tekanan darah sistolik dan diastolik yang bermakna antara sebelum dan setelah diberikan intervensi (Syamsyuriana Sabar, 2015).

Selain latihan isometric handgrip exercise terapi non farmakologis yang bisa dilakukan pada penderita hipertensi adalah dengan slow deep breathing exercise. Seperti yang dijelaskan oleh (Kozier. Erb, 2010) latihan pernapasan dalam dan lambat (slow deep breathing) merupakan terapi modalitas non farmakologis yang dapat memicu terjadinya peningkatan sensitivitas baroreflek dan mengurangi aktivitas simpatis dan aktivasi chemoreflex, yang menunjukkan efek berpotensi menguntungkan dalam hipertensi. Menurut Amandeep (2015) latihan slow deep breathing memiliki efek yang sangat bermanfaat untuk menurunkan tekanan darah pada penderita hipertensi. Hasil penelitian oleh Sepdianto et al, (2010) tentang penurunan tekanan darah dan kecemasan melalui slow deep breathing pada penderita hipertensi primer didapatkan hasil penurunan rata-rata tekanan darah sistolik dan diastolik, sistolik sebesar 18,78 mmHg dan diastolik $8,89 \mathrm{mmHg}$. Sehingga dapat diambil kesimpulan bahwa latihan slow deep breathing merupakan salah satu intervensi keperawatan yang bisa dilakukan secara mandiri serta dapat mempengaruhi terjadinya penurunan tekanan darah pada penderita hipertensi. Latihan slow deep breathing dapat memberikan stimulasi pada saraf otonom serta memberi efek pada respon saraf simpatis yang memicu terjadinya pelepasan neurotransmiter epinefrin dan noreprinefrin serta saraf parasimpatis yang melepaskan neurotransmiter asetilkolin. Respon saraf simpatis dan saraf parasimpatis berbanding terbalik saat melakukan latihan slow deep breathing, dimana saraf simpatis akan menignkatkan aktivitas tubuh sedangkan saraf parasimpatis menurunkan aktivitas tubuh (Pal, Velkumary, \& Madanmohan, 2004; Tarwoto, 2011).

Terapi nonfarmakologis yang dapat dilakukan untuk menurunkan tekanan darah pada penderita hipertensi salah satunya ialah dengan meningkatkan aktivitas fisik pasien dan dengan latihan pernapasan. Pada penelitian ini aktivitas fisik yang bisa diberikan kepada pasien dengan hipertensi adalah isometric handgrip exercise, sedangkan latihan pernapasan diberikan intervensi slow deep breathing exercise. Meskipun kedua intervensi ini sudah pernah dilakukan akan tetapi penerapannya di Indonesia masih jarang dan intervensi yang diberikan hanya fokus pada satu intervensi saja, khususnya di provinsi Bengkulu belum ada penelitian yang sama sebelumnya yaitu melihat perbedaan isometric handgrip exercise dan slow deep breathing exercise terhadap perubahan tekanan darah penderita hipertensi. 


\section{METODE PENELITIAN}

\section{Desain penelitian}

Penelitian ini menggunakan desain penelitian eksperimen semu atau yang disebut juga quasi experimental dengan two group pretest postest design. Penelitian ini dilaksanakan di wilayah kerja puskesmas Pasar Kepahiang dan wilayah kerja Puskesmas Bukit Sari Kabupaten Kepahiang Provinsi Bengkulu.

\section{Participant}

Populasi pada penelitian ini adalah pasien dengan hipertensi. Pasien direkrut dari puskemas Pasar Kepahiang dan puskesmas Bukit Sari, pasien yang diikutsertakan dalam penelitian adalah pasien yang memiliki kriteria tekanan darah sistolik $\geq 130 \mathrm{mmHg}$ dan tekanan darah diastolik $\geq 90 \mathrm{mmHg}$, responden mampu menggenggam handgrip, berumur $\geq 18-60$ tahun, melakukan intervensi pada saat bersama peneliti dan responden kooperatif serta bisa mengikuti instruksi, sementara pasien yang mengalami arthritis, cedera muskuloskeletal pada ekstremitas dan responden yang mengalami sindrom carpal tunnel atau nyeri pada tangan tidak diikutsertakan dalam penelitian ini. Penentuan besar sampel menggunakan rumus federer (Hidayat. A, 2011). Jumlah sampel dalam penelitian ini berjumlah 32 responden yang dibagi kedalam dua kelompok intervensi, yaitu kelompok isometric handgrip exercise $(\mathrm{n}=16)$ dan slow deep breathing exercise $(\mathrm{n}=16)$. Teknik pengambilan sampel menggunakan teknik purposive sampling.

\section{Data Colection Procedure}

Sebanyak 62 responden dikaji kelayakan dalam studi ini, dimana 32 orang setuju untuk berpartisipasi. Responden dalam penelitian ini adalah sebanyak 52\%. Partisipan yang telah setuju untuk dijadikan responden mengisi dan menandatangani informed concent dan mengisi seluruh kuesioner yang diberikan dengan jujur. Kemudian peneliti melakukan kunjungan ke rumah responden. Responden dibagi kedalam dua kelompok, pada kelompok intervensi isometric handgrip dilakukan selama lima hari dimana pengukuran tekanan darah dilakukan pada awal dan setelah intervensi pada hari ke 5, sedangkan pada kelompok slow deep breathing dilakukan selama 4 hari dimana pengukuran tekanan darah dilakukan pada awal dan setelah intervensi pada hari ke 4 .

\section{Intervention Group}

Intervensi dilakukan secara individual dan intervensi dilakukan oleh pasien setelah diajarkan oleh peneliti dan diimplementasikan pada kelompok intervensi isometric handgrip dan Slow deep breathing. Pada kelompok Intervensi isometric handgrip exercise diberikan selama 5 hari berturut-turut dengan frekuensi 1 kali sehari dengan bantuan handgrip. Jumlah total durasi selama latihan sebanyak 180 detik atau 3 menit dan pengukuran tekanan darah setelah intervensi dilakukan setelah istirahat 5 menit. Sedangkan kelompok slow deep breathing exercise diberikan selama 4 hari dengan frekuensi 2 kali sehari, responden dapat melakukan 13 kali SDB 6x / menit dengan istirahat 10 detik selama 15 menit yang diberikan.

\section{Ethical Consideration}

Penelitian ini dilakukan setelah mendapat persetujuan dari dewan peninjau etika atau telah lolos kaji etik di Universitas Muhammadiyah Jakarta. Peneliti telah menjelaskan tentang penelitian ini kepada calon responden termasuk tujuan, metode, 
manfaat, risiko serta prosedur intervensi yang akan dilakukan oleh calon responden selama proses penelitian. Peneliti menjamin kerahasiaan pada responden dan memberikan hak kepada responden bahwa mereka bisa keluar pada saat proses penelitian kapanpun tanpa implikasi untuk perlakuan selanjutnya.

\section{Statistik Analisis}

Analisa data ini akan diolah dengan menggunakan aplikasi SPSS 19. Deskritif statistik dilakukan untuk mengetahui gambaran karakteristik sampel dan gambaran tekanan darah pada awal pengukuran sebelum dilakukan. Uji parametrik paired sample $t$ test digunakan untuk melihat ada tidaknya pengaruh atau perubahan tekanan darah sebelum dan setelah diberikan intervensi.

\section{HASIL PENELITIAN \\ Karakteristik responden}

Tabel. 1

Distribusi Responden Berdasarkan Umur, Jenis Kelamin, Riwayat Hipertensi Keluarga dan Pengobatan $(n=32)$

\begin{tabular}{|c|c|c|c|c|c|c|c|c|c|c|c|}
\hline \multirow[t]{2}{*}{ Karakteristik } & \multicolumn{4}{|c|}{$\begin{array}{l}\text { Isometric Handgrip } \\
\text { Exercise }(\mathrm{n}=16)\end{array}$} & \multicolumn{4}{|c|}{$\begin{array}{l}\text { Slow Deep Breathing } \\
\text { Exercise }(\mathrm{n}-16)\end{array}$} & \multicolumn{2}{|c|}{ Total } & \multirow[t]{2}{*}{$\underset{\text { value }^{a}}{\mathrm{p}}$} \\
\hline & (f) & $(\%)$ & Mean & SD & (f) & $(\%)$ & Mean & SD & (f) & $(\%)$ & \\
\hline Usia & - & - & 49,25 & 2,91 & - & - & 49,94 & 3,28 & - & - & 0,330 \\
\hline \multicolumn{12}{|l|}{ Jenis Kelamin } \\
\hline Laki-Laki & 10 & 31,3 & - & - & 9 & 28,1 & - & - & 19 & 59,4 & \multirow{2}{*}{0,510} \\
\hline Perempuan & 6 & 18,7 & - & - & 7 & 21,9 & - & - & 13 & 40,6 & \\
\hline \multicolumn{12}{|l|}{ Riwayat Keluarga } \\
\hline Ada & 5 & 15,6 & - & - & 6 & 18,7 & - & - & 11 & 34,4 & \multirow{2}{*}{0,481} \\
\hline Tidak Ada & 11 & 34,4 & - & - & 10 & 31,3 & - & - & 21 & 65,6 & \\
\hline \multicolumn{12}{|l|}{ Pengobatan } \\
\hline Teratur & 12 & 37,5 & - & - & 11 & 34,4 & - & - & 23 & 71,7 & \multirow{2}{*}{0,452} \\
\hline Tidak Teratur & 4 & 12,5 & - & - & 5 & 15,6 & - & - & 9 & 28,1 & \\
\hline
\end{tabular}

Pada penelitian ini rata-rata umur responden pada dua kelompok adalah 50 tahun dengan standar deviasi 3,09, mayoritas responden adalah laki-laki ( $\mathrm{n}=19 ; 59,4 \%)$, memiliki riwayat keluarga hipertensi $(\mathrm{n}=21 ; 65,6 \%)$ dan melakukan pengobatan secara tidak teratur $(\mathrm{n}=23 ; 71,7 \%)$. Selain itu, karakteristik responden untuk kedua kelompok intervensi setara dalam jenis kelamin, riwayat keluarga hipertensi dan pengobatan karena diperoleh $\mathrm{p}$ value $>0,05$.

Tabel. 2

Tekanan Darah Sistolik Responden Sebelum dan Setelah Diberikan Intervensi $(n=32)$

\begin{tabular}{llcccccc}
\hline \multicolumn{1}{c}{ Variabel } & \multirow{2}{*}{ Kelompok } & \multirow{2}{*}{ N } & \multirow{2}{*}{ Mean } & \multirow{2}{*}{ SD } & \multicolumn{2}{c}{$95 \%$ CI } & p value $^{a}$ \\
& & & & & Min & Maks & \\
Tekanan Darah Sistolik & Handgrip & 16 & 156,06 & 8,64 & 151,88 & 160,25 & \\
Sebelum Intervensi & SBD & 16 & 157,75 & 6,06 & 154,88 & 160,38 & 0,151 \\
& Total & 32 & 156,91 & 7,35 & & & \\
Tekanan Darah Sistolik & Handgrip & 16 & 153,69 & 8,56 & 149,63 & 157,75 & \multirow{2}{*}{0,098} \\
Setelah Intervensi & SBD & 16 & 155,06 & 5,77 & 152,44 & 157,75 & \\
& Total & 32 & 154,38 & 7,17 & & & \\
\hline
\end{tabular}


Berdasarkan tabel 2 dapat dilihat bahwa baik pada kelompok intervensi isometric handgrip exercise maupun kelompok intervensi slow deep breathing exercise didapatkan nilai tekanan darah sistolik diatas $140 \mathrm{mmHg}$ yaitu sebesar 159,91 mmHg. Tidak ada perbedaan yang ditemukan pada kedua kelompok antara kelompok isometric handgrip dengan kelompok intevensi slow deep breathing $\mathrm{p}$ value $>0,05$.

Tabel. 3

Tekanan Darah Diastolik Responden Sebelum dan Setelah Diberikan Intervensi $(n=32)$

\begin{tabular}{llcccccc}
\hline \multicolumn{1}{c}{ Variabel } & \multirow{2}{*}{ Kelompok } & \multirow{2}{*}{ Mean } & SD & \multicolumn{2}{c}{ 95\% CI } & p value \\
& & & & & Min & Mak & \\
\hline \multirow{2}{*}{ Tekanan Darah Diastolik } & Handgrip & 16 & 99,34 & 3,11 & 98,06 & 101,13 & \multirow{2}{*}{0,929} \\
Sebelum Intervensi & SBD & 16 & 100,81 & 3,15 & 99,38 & 102,31 & \\
& Total & 32 & 100,01 & 3,13 & & & \\
Tekanan Darah Diastolik & Handgrip & 16 & 98,76 & 2,77 & 96.00 & 98,63 & \multirow{2}{*}{0,199} \\
Setelah Intervensi & SBD & 16 & 96,94 & 1,65 & 96,13 & 97,75 & \\
& Total & 32 & 97,85 & 2,21 & & & \\
\hline
\end{tabular}

Berdasarkan tabel 3 dapat dilihat bahwa baik pada kelompok intervensi isometric handgrip exercise maupun kelompok intervensi slow deep breathing exercise didapatkan nilai tekanan darah diastolik diatas $90 \mathrm{mmHg}$ yaitu sebesar 100,01 $\mathrm{mmHg}$ sebelum diberikan intervensi. Tidak ada perbedaan yang ditemukan pada kedua kelompok antara kelompok isometric handgrip dengan kelompok intevensi slow deep breathing $\mathrm{p}$ value $>0,05$.

Tekanan darah pada kedua kelompok baik isometric handgrip exercise maupun slow deep breathing exercise termasuk kedalam kategori hipertensi derajat II yaitu berada pada rentang tekanan darah sistolik $\geq 140 \mathrm{mmHg}$ dan tekanan darah diastolik $\geq$ $90 \mathrm{mmHg}$.

Tabel. 4

Distribusi Rata-Rata Tekanan Darah Sistolik dan Diastolik Sebelum dan Setelah Intervensi $(n=32)$

\begin{tabular}{|c|c|c|c|c|c|c|}
\hline Variabel & Kelompok & & Mean & $\mathrm{SD}$ & t value & $\mathrm{p}$ value \\
\hline \multirow{4}{*}{ Sistolik } & & Sebelum & 156,06 & 8,64 & \multirow{2}{*}{8,279} & \multirow{2}{*}{0,000} \\
\hline & Isometrlc Handgrip & Setelah & 153,69 & 8,56 & & \\
\hline & \multirow{2}{*}{ Slow Deep Breathing } & Sebelum & 157,75 & 6,06 & \multirow{2}{*}{3,632} & \multirow{2}{*}{0,002} \\
\hline & & Setelah & 155,06 & 5,77 & & \\
\hline \multirow{3}{*}{ Diastolik } & Isometric Handrin & Sebelum & 99,63 & 3,28 & \multirow{2}{*}{6,154} & \multirow{2}{*}{0,000} \\
\hline & 1sometric nanagrip & Setelah & 97,25 & 2,72 & & \\
\hline & Slow Deep Breathing & Sebelum & 100,81 & 3,15 & 4,226 & 0,001 \\
\hline
\end{tabular}

Partisipan pada kelompok intervensi isometric handgrip exercise mengalami penurunan tekanan darah sistolik sebesar 2,37 $\mathrm{mmHg}$ dan tekanan darah diastolik sebesar 2,38 mmHg. Sedangkan pada kelompok intervensi slow deep breathing exercise mengalami penurunan tekanan darah sistolik sebesar $2,69 \mathrm{mmHg}$ dan tekanan darah diastolik $3,87 \mathrm{mmHg}$. Analisis lebih lanjut menunjukkan adanya penurunan tekanan darahsistolik sebelum dan setelah diberikan intervensi pada kelompok isometric handgrip exercise dengan ( $\mathrm{t}$ value $=8,279$, $\mathrm{p}$ value $=0,000$ ) dan pada kelompok slow deep breathing exercise $(\mathrm{t}$ value $=3,632, \mathrm{p}$ value $=0,002)$. Serta terjadi penurunan tekanan darah diastolik sebelum dan setelah diberikan intervensi pada kelompok 
isometric handgrip exercise dengan ( $\mathrm{t}$ value $=6,154, \mathrm{p}$ value $=0,000$ ) dan pada kelompok slow deep breathing exercise $(\mathrm{t}$ value $=4,226$, $\mathrm{p}$ value $=0,001)$.

\section{PEMBAHASAN}

\section{Karakteristik Responden}

Hasil penelitian menunjukkan rata-rata umur responden pada kelompok intervensi slow deep breathing exercise lebih tinggi daripada kelompok intervensi isometric handgrip exercise, namun pada hasil analisis tidak ada perbedaan rata-rata yang bermakna antara umur responden kelompok isometric handgrip exercise dengan slow deep breathing exercise karena memiliki varian yang sama. Hasil penelitian ini sama dengan penelitian sebelumnya yang menjelaskan bahwa kelompok umur mempengaruhi terjadinya hipertensi (Sundari, Aulani'am, S, \& Widodo, 2013). Semakin lanjut usia seseorang, maka tekanan darah akan semakin tinggi karena beberapa faktor seperti elastisitas pembuluh darah yang berkurang, fungsi ginjal sebagai penyeimbang tekanan darah akan menurun (Hananta, 2011). Umur adalah salah satu faktor yang dapat mempengaruhi kondisi kesehatan seseorang. Semakin meningkatnya umur, maka risiko mendapat hipertensi juga akan ikut meningkat. Salah satu faktor risiko yang mempengaruhi hipertensi adalah usia karena seiring bertambahnya usia maka semakin tinggi pula risiko terjadinya hipertensi. Seiring dengan bertambahnya usia, risiko penyakit hipertensi akan semakin meningkat hal ini disebabkan oleh pembuluh darah, hormon dan jantung yang dipengaruhi oleh terjadinya perubahan alamiah dalam tubuh (Triyanto, 2014).

Sebagian besar jenis kelamin responden dalam penelitian ini adalah laki-laki. Meta analisis Danaei dkk juga menemukan rerata tekanan darah sistolik secara global lebih tinggi pada laki-laki dibanding perempuan. Hal ini dapat disebabkan keberadaan faktor risiko seperti merokok dan konsumsi kopi yang cenderung lebih tinggi pada lakilaki dibanding perempuan (Widiana, Made Restu, 2017). Risiko pada laki-laki dan perempuan hampir sama antara usia 55 sampai 74 tahun, kemudian setelah usia 74 tahun, wanita berisiko lebih besar (Black, J.M., \& Hawks, 2009). Menurut Suiraoka (2012) Hal ini juga dikarenakan pria banyak mempunyai faktor risiko yang mempengaruhi terjadinya hipertensi seperti merokok, kurang nyaman terhadap pekerjaan dan makan tidak terkontrol. Biasanya wanita akan mengalami peningkatan hipertensi setelah masa menopause (Suiraoka, 2012).

Hasil penelitian ini sejalan dengan penelitian sebelumnya yang menyebutkan bahwa prevalensi penderita hipertensi lebih banyak pada jenis kelamin laki-laki, daripada perempuan (Heriziana, 2017). Jenis kelamin dapat mempengaruhi kadar hormon yang dimiliki seseorang. Esterogen yang lebih banyak dimiliki oleh wanita diketahui dapat menjadi faktor protektif/perlindungan pembuluh darah, sehingga penyakit jantung dan pembuluh darah (kardiovaskuler) lebih banyak ditemukan pada pria yang kadar esterogennya lebih rendah daripada wanita (Hananta, 2011; Heriziana, 2017).

Responden dalam penelitian ini sebagian besar memiliki riwayat keluarga yang menderita hipertensi. Gen dapat berinteraksi dengan yang lainnya dan juga lingkungan yang dapat menyebabkan tekanan darah naik dari waktu ke waktu (hipertensi dianggap poligenik dan multifaktorial), hal ini berhubungan dengan terjadinya peningkatan kadar natrium intraselular serta penurunan rasio kalsium-natrium. Seseorang yang lahir dari orang tua dengan memiliki riwayat hipertensi akan memiliki risiko lebih tinggi untuk menderita hipertensi (Black, J.M., \& Hawks, 2009). Penelitian ini sejalan dengan 
penelitian sebelumnya yang menyebutkan bahwa riwayat hipertensi keluarga dengan hipertensi mempengaruhi kejadian hipertensi (Heriziana, 2017). Riwayat hipertensi yang didapat dari orang tua maka dugaan terjadinya hipertensi primer pada seseorang akan cukup besar. Hal ini bisa terjadi karena adanya sifat yang diwariskan melalui gen. Faktor keturunan memang memiliki peran besar terhadap munculnya hipertensi. Hal itu terbukti dengan ditemukannya kejadian bahwa dari 10 orang penderita hipertensi, $90 \%$ diantaranya terjadi karena mereka mempunyai gen yang dapat menyebabkan munculnya hipertensi. Meski demikian gen dapat menjadikan seseorang sebagai penderita hipertensi karena ada faktor pemicu eksternal yang lain (Heriziana, 2017; Sutanto, 2010).

Pada penelitian ini sebagian besar responden memiliki riwayat pengobatan yang tidak teratur. Dr. Sandosh Padmanabhan, seorang peneliti dari Universitas Glasgow dilansir dari Daily Mail mengatakan bahwa tekanan darah secara alami dapat berubahubah karena interaksi yang kompleks dari berbagai faktor salah satunya adalah apabilaseseorang tidak minum obat secara teratur. Lanjut Pradmanabhan, pasien yang gagal dalam menuruti dosis dalam minum obat makaakanmemicu terjadinya peningkatan risiko serangan jantung atau stroke mereka hingga lebih dari $40 \%$ (Hellosehat, 2018).

\section{Pengaruh Isometric Handgrip Exercie terhadap Tekanan Darah}

Hasil penelitian ini menunjukkan bahwa pasien hipertensi yang diberikan latihan isometric handgrip exercise selama 5 hari berturut-turut memperlihatkan penurunan tekanan darah sistolik dan diastolik yang bermakna antara sebelum dan setelah melakukan Isometric Handgrip Exercise. Hasil dalam penelitian ini didukung oleh penelitian sebelumnya yang mengatakan bahwa latihan isometrik dengan menggunakan handgrip secara bermakna dalam menurunkan tekanan darah sistolik sebesar $2,4 \mathrm{mmHg}$ $(\mathrm{p}$ value $=0,036)$ dan tekanan darah diastolik sebesar $2,5 \mathrm{mmHg}(\mathrm{p}$ value $=0,0079)$ (Mortimer, 2011). Latihan isometric handgrip dapat menurunkan reaktivitas kardiovaskuler terhadap stressor psikofisiologis pada orang yang menderita hipertensi (Badrov et al, 2013). Pada penelitian, 5 menit setelah satu kali kontraksi bilateral handgrip terjadi peningkatan nadi yang dapat diinterpretasikan sebagai perubahan keseimbangan neurokardiak yaitu dengan meningkatnya respon vagal atau terjadinya penurunan modulasi simpatik (Millar, MacDonald, Bray, \& McCartney, 2009).

Latihan isometric mengakibatkan penekanan otot pada pembuluh darah yang akan menghasilkan stimulus iskemik dan menimbulkan stimulus sehingga terjadi mekanisme shear stress (Guyton, A.C, Hall, 2008). Stimulus iskemik menginduksi peningkatan aliran arteri brakialis untuk menurunkan efek langsung iskemia pada pembuluh darah tersebut. Ketika tekanan dilepaskan, aliran darah pembuluh darah lengan bawah membesar dikarenakan terjadinya dilatasi pada pembuluh darah distal yang akan menginduksi stimulus shear stress pada arteri brakialis (Mcgowan, Levy, Mccartney, \& Macdonald, 2007). Mekanisme shear stress menimbulkan pelepasan turunan Nitrit Oksid (NO)-endotelium yang diproduksi oleh sel endotel sebagai vasodilator pembuluh darah (Mcgowan et al, 2007). NO merupakan mediator kunci dari sel endotel dimana sel endotel adalah bagian dalam lumen dari pembuluh darah yang berada diseluruh tubuh dan memiliki peran penting sebagai penghubung antara sirkulasi darah dan sel-sel otot polos pada pembuluh darah. Sejumlah NO juga akan berdifusi ke dinding arteri dan vena (otot polos) serta mengaktivasi enzim yang akan merangsang dan memicu untuk terjadinya relaksasi pada otot yang memungkinkan pembuluh darah membesar 
(peningkatan diameter pembuluh darah) yang mengakibatkan darah menjadi lancar dan terjadi penurunan tekanan darah (Widiastuti, 2010).

Penemuan terbaru menjelaskan bahwa terjadi peningkatan kapasitas istirahat pada system produksi, pelepasan dan/atau penggunaan NO-dilator memiliki kontribusi pada penurunan tekanan darah sistolik setelah latihan. Selain itu stimulus hyperemia reaktif berkontribusi dalam pelepasan substansi vasodilator lain termasuk prostasiklin dan metabolit iskemik (Mcgowan et al, 2007). Dengan demikian, penurunan puncak reaktivitas aliran darah hyperemia akan berpengaruh terhadap terjadinya perubahan fungsi otot polos pembuluh darah dan menjadi dasar dalam terjadinya perubahan struktur pembuluh darah sehingga menyebabkan penurunan resistensi perifer (Mcgowan et al, 2007).

Berdasarkan hasil diatas, meskipun penurunan tekanan darah yang didapatkan tidak terlalu besar, namun dilansir dari rilis media yang diunggah pada laman PD PERSI, dikatakan bahwa penurunan tekanan darah hingga $2 \mathrm{mmHg}$ tekanan darah dapat mengurangi risiko kematian akibat penyakit jantung koroner sebesar $7 \%$ dan risiko kematian akibat stroke sebesar 10\% (Hellosehat, 2018). Maka rerata penurunan tekanan darah pada penelitian ini diharapkan bisa memberikan manfaat yang baik dalam menurunkan angka kesakitan dan kematian akibat hipertensi. Hal lain yang dapat menyebabkan kecilnya frekuensi penurunan tekanan darah adalah karena tingkat pengobatan responden yang sebagian besar tidak teratur karena keteraturan minum obat anti hipertensi bisa menjadi salah satu faktor yang mempengaruhi peningkatan atau penurunan tekanan darah. Adanya penyakit lain juga dapat menghambat latihan dalam penurunan tekanan darah.

Hasil penelitian ini telah menunjukkan bahwa dengan memberikan intervensi isometric handgrip exercise selama 5 hari berturut-turut dengan frekuensi 1 kali dalam sehari efektif dapat menurunkan tekanan darah.

\section{Pengaruh Slow Deep Breathing Exercise terhadap Perubahan Tekanan Darah}

Hasil penelitian ini menunjukkan bahwa pasien hipertensi yang diberikan latihan slow deep breathing exercise selama 4 hari dengan frekuensi 2 kali dalam sehari memperlihatkan perubahan tekanan darah sistolik dan diastolik yang bermakna antara sebelum dan setelah melakukan slow deep breathing exercise. Penelitian ini sejalan dengan penelitian sebelumnya yang menjelaskan bahwa terdapat perbedaan yang signifikan pada tekanan darah sistolik serta diastolik sebelum dan setelah satu minggu melakukan latihan slow deep breathing (Abd, Naglaa, Hanafy, \& El-naby, 2014).

Latihan SDB meningkatkan kadar oksigen dalam jaringan tubuh. Peningkatan oksigen mengaktifkan chemoreceptor yang sensitif terhadap perubahan kandungan oksigen dalam jaringan tubuh dan kemudian chemoreceptor mentransmisikam sinyal syaraf ke pusat pernapasan tepat di medula oblongata yang juga merupakan pusat meduler kardiovaskular. Sinyal yang ditransmisikan ke otak akan menyebabkan aktivitas saraf parasimpatik meningkat dan menurunkan aktivitas saraf simpatis (Diest, Widjaja, \& Vansteenwegen, 2014). Pernyataan ini dikuatkan oleh (D. E. Anderson, McNeely, \& Windham, 2010) yang menyebutkan bahwa teknik SDB akan menghasilkan sinyal yang mengaktifkan reflek baroreseptor melalui peningkatan tekanan darah arteri di pembuluh darah karena peningkatan volume stroke dan bulk heart di jantung kiri. Sebagai akibatnya akan ada penurunan tekanan darah dari aktivasi reflek baroreseptor yang mengirimkan sinyal ke pusat kardiovaskular (Anderson, 2015). 
Selanjutnya (Turankar et al, 2013) menemukan bahwa pernapasan dalam dan latihan pernapasan yang lambat secara teratur dapat meningkatkan sensitivitas barokeptor dan aktivitas kemoreseptor untuk menurunkan tekanan darah pada klien hipertensi. Dorongan aferen dari baroreceptor mencapai pusat jantung yang akan merangsang aktivitas saraf parasimpatis dan menghambat pusat simpatis (cardio accelerator), menghasilkan vasodilatasi sistemik, penurunan denyut jantung dan daya (Ignatavicius, Workman, 2006). Hal ini juga sejalan dengan hasil penelitian (Pramanik et al, 2009) yang menyatakan bahwa setelah bernapas dalam-dalam (frekuensi pernapasan 6x / menit) selama lima menit, terjadi penurunan darah yang signifikan, baik tekanan darah sistolik maupun diastolik, serta penurunan denyut jantung yang ringan.

Pernapasan lambat meningkatkan aktivitas vagal oleh karena itu dapat menurunkan denyut jantung dan tekanan darah. Mekanisme ini dikaitkan dengan peningkatan tonus vagal dan dengan mengurangi pengeluaran simpatik. Peningkatan reaktivitas simpatis dan parasimpatis merupakan salah satu mekanisme yanf terkait pada orang yang berlatih latihan pernapasan lambat (Singh, Jain, 2009). Denyut jantung meningkat selama inspirasi dan menurun selama ekspirasi. Rekaman dari saraf otonom jantung mengungkapkan bahwa aktivitas saraf meningkat pada serabut simpatis selama inspirasi dan peningkatan serabut vagal selama ekspirasi (Ahmad, 2013; Berne, Levy, 2009).

Hasil penelitian ini menunjukkan bahwa intervensi slow deep breathing yang sudah diberikan selama 4 hari dengan frekuensi 2 kali dalam sehari dapat menurunkan tekanan darah secara signifikan.

\section{SIMPULAN}

Rata-rata umur responden adalah 50 tahun, mayoritas responden adalah laki-laki, memiliki riwayat keluarga hipertensi dan riwayat pengobatan tidak teratur. Terdapat perubahaan tekanan darah sistolik dan diastolik yang bermakna pada kelompok isometric handgrip exercise sebelum dan setelah melakukan intervensi. Terdapat perubahaan tekanan darah sistolik dan diastolik yang bermakna pada kelompok slow deep breathing exercise sebelum dan setelah melakukan intervensi.

Ada perbedaan selisih penurunan tekanan darah sistolik dan diastolik pada kelompok intervensi isometric handgrip exercise dan slow deep breathing exercise.

Intervensi isometric handgrip exercise dan slow deep breathing exercise yang diberikan pada penelitian ini efektif dalam menurunkan tekanan darah pada pasien hipertensi.

Peneliti menyimpulkan bahwa secara klinis kedua kelompok intervensi efektif dalam menurunkan tekanan darah pada pasien hipertensi dan dalam hal ini perawat memiliki peran yang penting agar intervensi ini dapat digunakan oleh masyarakat khususnya pasien hipertensi. Peneliti menganggap bahwa intervensi ini memiliki manfaat yang baik dalam upaya menurunkan tekanan darah. Meskipun penurunan tekanan darah sistolik dan diastolik tidak terlalu tinggi, akan tetapi intervensi kedua kelompok ini diharapkan dapat digunakan sebagai terapi non farmakologi yang membantu pasien dalam mengontrol atau menurunkan tekanan darah selain mengontrol gaya hidup sehari-hari. 


\section{SARAN}

Disarankan kepeda pihak-pihak terkait, antara lain :

Bagi puskesmas Pasar Kepahiang dan Puskesmas Bukit Sari diharapkan dapat mengembangkan kebijakan untuk menerapkan isometric handgrip exercise dan slow deep breathing exercise sebagai salah satu terapi non farmakologi untuk pasien dengan hipertensi dan menerapkan kepada masyarakat sebagai salah satu alternatif dalam membantu menurunkan tekanan darah selain dengan modifikasi gaya hidup.

Bagi pelayanan keperawatan diharapkan dapat memasukkan isometric handgrip exercise dan slow deep breathing exercise sebagai bahan kajian pendidikan keperawatan sebagai salah satu terapi non farmakologi dalam upaya menurunkan tekanan darah pada pasien hipertensi.

Bagi penelitian selanjutnya perlu dikembangkan penelitian lanjutan dengan menambah durasi waktu penelitian baik melakukan intervensi isometric handgrip exercise maupun slow deep breathing exercise sehingga memperoleh pola dan gambaran secara lebih spesifik terkait waktu efektif penurunan tekanan darah pada kedua kelompok intervensi. Perlu dikembangkan penelitian lebih lanjut tentang isometric handgrip exercise dan slow deep breathing exercise dengan menghubungkan variabel perancu serta dilakukannya analisa sampai dengan uji multivariat. 


\section{DAFTAR PUSTAKA}

Abd, L., Naglaa, E. M., Hanafy, F., \& El-naby, A. G. A. (2014). Effect of Slow Deep Breathing Exercise on Blood Pressure and Heart Rate among Newly Diagnosed Patients with Essential Hypertension, 5(4), 36-45

Ahmad, S. (2013). The Influence Of The 2: 1 Yogic Breathing Technique on Essential Hypertension, 57(1), 38-44

Amandeep. (2015). Effectiveness of Abdominal Breathing Exercise on Blood Pressure among Hypertensive Patients. International Journal of Therapeutic Applications 24, 39-49. Issn 2320-138x

Anderson, D. E., McNeely, J. D., \& Windham, B. G. (2010). Regular Slow-Breathing Exercise Effects on Blood Pressure and Breathing Patterns at Rest. Journal of Human Hypertension, 24(12), 807-813. https://doi.org/10.1038/jhh.2010.18

Anderson, E. (2015). Effect of Slow Deep Breathing to Blood Pressure and Heart Rate Hypertensive Patients at Adventist Hospital in Bandar Lampung, Indonesia

Badrov, M. B., Horton, S., Millar, P. J., \& Mcgowan, C. L. (2013). Cardiovascular Stress Reactivity Tasks Successfully Predict the Hypotensive Response of Isometric Handgrip Training in Hypertensives. Psychophysiology, 50(4), 407414. https://doi.org/10.1111/psyp.12031

Berne \& Levy. (2009). Regulation of the Heart and Vasculature. In: Koeppen BM and Stanton BA.Berne and Levy physiology (6th ed.). Philadelpia: Thomson press

Black, J.M., \& Hawks, J. H. (2009). Medical Surgical Nursing: Clinical Management for Positive Outcomes Vol. 2 (8th ed.). Singapore: Elsevier Pte Ltd

Carlson, D. J., Dieberg, G., Hess, N. C., Millar, P. J., \& Smart, N. A. (2014). Isometric Exercise Training for Blood Pressure Management: A Systematic Review and Meta-Analysis. Mayo Clinic Proceedings, 89(3), 327-334. https://doi.org/10.1016/j.mayocp.2013.10.030

Diest, I. Van, Widjaja, D., \& Vansteenwegen, D. (2014). Inhalation / Exhalation Ratio Modulates the Effect of Slow Breathing on Heart Rate Variability and Relaxation Inhalation / Exhalation Ratio Modulates the Effect of Slow Breathing on Heart Rate Variability and Relaxation, (May 2015). https://doi.org/10.1007/s10484-0149253-x

Dinkes Provinsi bengkulu. (2016). Profil Kesehatan Provinsi Bengkulu Tahun 2015, 1154

Garg, R., Malhotra, V., Dhar, U., \& Tripathi, Y. (2013). The Isometric Handgrip Exercise as a Test for Unmasking Hypertension in the Offsprings of Hypertensive Parents. Journal of Clinical and Diagnostic Research, 7(6), 996-999. https://doi.org/10.7860/JCDR/2013/5094.3043

Guyton, A.C \& Hall, J. (2008). Buku Ajar Fisiologi Kedokteran (11th ed.). Jakarta: EGC

Hananta, D. (2011). Deteksi Dini dan Pencegahan 7 Penyakit Penyebab Mati Muda. (M. Pressindo, Ed.) (Cetakan). Yogyakarta

Hellosehat. (2018a). Apakah Hipertensi Bisa Disembuhkan? Retrieved July 20, 2018, from https://www.google.co.id/amp/s/hellosehat.com/hidup-sehat/tipssehat/hipertensi-bisa-sembuh-atau-tidak/amp/

Hellosehat. (2018b). Obat Darah Tinggi harus Diminum Bahkan Saat Tensi Darah Rendah. Retrieved from http://www.google.co.id/amp/s/hellosehat.com/hidupsehat/tips-sehat/kapan-minum-obat-darah-tinggi/amp/ 
Heriziana. (2017). The Risk Factors Incidence of Hypertension in Puskesmas Basuki Rahmat Palembang Menurut Data Organisasi Kesehatan Dunia, 31-39

Hidayat, A. (2011). Metode Penelitian Keperawatan dan Teknik Analisa Data. Jakarta: Salemba Medika

Ignatavicius \& Workman. (2006). Medical Surgical Nurshing Critical Thingking for Collaborative Care (Vol. 2). Ohia: Elsevier sauders

James, P. A., Oparil, S., Carter, B. L., Cushman, W. C., Dennison-Himmelfarb, C., Handler, J., Ortiz, E. (2014). Evidence-Based Guideline for the Management of High Blood Pressure in Adults. Jama, 311(5), 507. https://doi.org/10.1001/jama.2013.284427

Kozier. Erb, B. S. (2010). Buku Ajar Fundamental Keperawatan: Konsep, Proses \& Praktik, Volume: 1 (7th ed.). Jakarta: EGC

Mcgowan, C. L., Levy, A. S., Mccartney, N., \& Macdonald, M. J. (2007). Isometric Handgrip Training Does not Improve Flow-Mediated Dilation in Subjects with Normal Blood Pressure. Clinical Science, 112(7), 403-409. https://doi.org/10.1042/CS20060195

McGowan, C. L., Proctor, D. N., Swaine, I., Brook, R. D., Jackson, E. A., \& Levy, P. D. (2017). Isometric Handgrip as an Adjunct for Blood Pressure Control: a Primer for Clinicians. Current Hypertension Reports, 19(6). https://doi.org/10.1007/s11906-017-0748-8

Millar, P. J., MacDonald, M. J., Bray, S. R., \& McCartney, N. (2009). Isometric Handgrip Exercise Improves Acute Neurocardiac Regulation. European Journal of Applied Physiology, 107(5), 509-515. https://doi.org/10.1007/s00421-0091142-2

Mortimer. (2011). Effect of Short-Term Isometric Handgrip Training on Blood Pressure in Middle-Aged Females, 22(5). Retrieved from www.cvja.co.za

Pal, G. K., Velkumary, S., \& Madanmohan, A. (2004). Effect of Short-Term Practice of Breathing Exercises on Autonomic Functions in Normal Human Volunteers. Indian Journal of Medical Research, 120(2), 115-121. https://doi.org/10.1161/Hypertensionaha.112.194225

Parlindungan, T., \& Lukitasari, A. (2016). Latihan Isometrik Bermanfaat Menurunkan Tekanan Darah pada Penderita Hipertensi Helpful Isometric Exercise Lowers Blood Pressure in Patients Hypertension

Pramanik, T., Ph, D., Sharma, H. O., Mishra, S., Mishra, A., Prajapati, R., Singh, S. (2009). on Blood Pressure and Heart Rate, 15(3), 293-295. https://doi.org/10.1089/acm.2008.0440

Riskesdas. (2013). Riset Kesehatan Dasar (RISKESDAS) 2013. Laporan Nasional 2013, 1-384. https://doi.org/1 Desember 2013

Sepdianto, T. C., Nurachmah, E., Gayatri, D., Kesehatan, P., Malang, D., \& Tengah, J. (2010). Penurunan Tekanan Darah dan Kecemasan melalui Latihan Slow Deep Breathing pada Pasien Hipertensi Primer, 2-6

Singh, N. P., \& Jain, A. K. (2009). Effect of Slow- and Fast-Breathing Exercises on Autonomic, 15(7), 711-717

Suiraoka. (2012). Penyakit Degeneratif, Mengenal, Mencegah dan Mengurangi Faktor Risiko 9 Penyakit Degeneratif. Yogyakarta: Nuha Medika

Sundari, S., Aulani'am, A., S, D. W., \& Widodo, M. A. (2013). Faktor Risiko Non Genetik dan Polimorfisme Promoter RegionGen CYP11B2 Varian T (-344) C Aldosterone Synthase pada Pasien Hipertensi Esensial di Wilayah Pantai dan 
Pegunungan. Jurnal Kedokteran Brawijaya, 27(3), 169-177. Retrieved from http://jkb.ub.ac.id/index.php/jkb/article/view/345

Sutanto. (2010). Cekal (Cegah dan Tangkal) Penyakit Modern: Hipertensi, Stroke, Jantung, Kolesterol, dan Diabetes (gejala-gejala, pencegahan dan pengendalian). Yogyakarta

Syamsyuriana Sabar. (2015). Pengaruh Isometric Handgrip Exercise terhadap Perubahan Tekanan Darah. Universitas Indonesia. Retrieved from http://lib.ui.ac.id/detail?id=20404253\&lokasi=lokal

Tarwoto. (2011). Pengaruh Latihan Slow Deep Breathing terhadap Intensitas Nyeri Kepala Akut pada Pasien Cedera Kepala Ringan

Triyanto. (2014). Pelayanan Keperawatan Bagi Penderita Hipertensi Secara Terpadu. Yogyakarta: Graha Ilmu

Turankar, A. V., Jain, S., Patel, S. B., Sinha, S. R., Joshi, A. D., Vallish, B. N., ... Turankar, S. A. (2013). Effects of Slow Breathing Exercise on Cardiovascular Functions, Pulmonary Functions \& Galvanic Skin Resistance in Healthy Human Volunteers - A Pilot Study. The Indian Journal of Medical Research, 137(5), 916-921

WHO (World Health Organization). (2015). Prevalence of Raised Blood Pressure. Retrieved from http:/gamapserver.who.int/gho/interactive_charts/ncd/risk_factors/blood_pressure _prevalence/atlas.html

Widiana, Made Restu. (2017). Prevalensi dan Karakteristik Hipertensi pada Pralansia dan Lansia di Dusun Tengah, Desa Ulakan, Kecamatan Manggis, 6(8)

Widiastuti. (2010). Perbedaan kadar Nitric Oxide dan Derajat Stenosis Pada Penderita Penyakit Jantung Koroner dengan dan Tanpa Diabetes Melitus. Semarang 